\title{
High Definition Oscillometric Blood Pressure Measurement in Apparently Healthy Dogs: A Clinical Study
}

\author{
Meenu Bala ${ }^{1}$, Sujata Turkar ${ }^{1 *}$, Neetu Saini ${ }^{1},{\text { Charanjit Singh } \text { Randhawa }^{1} \text { and Neeraj Kashyap }}^{2}$ \\ ${ }^{1}$ Dept. of Veterinary Medicine, Guru Angad Dev Veterinary and Animal Sciences University, Ludhiana, Punjab, INDIA \\ ${ }^{2}$ Dept. of Animal Genetics and Breeding, Guru Angad Dev Veterinary and Animal Sciences University, Ludhiana, Punjab, INDIA \\ *Corresponding author: S Turkar; E-mail: sujataturkar@gmail.com
}

Received: 18 April, 2021

Revised: 08 June, 2021

Accepted: 16 June, 2021

\begin{abstract}
Present clinical study was conducted in 170 apparently healthy dogs for monitoring of blood pressure (Systolic Arterial Pressure: SAP, Diastolic Arterial Pressure: DAP and Mean Arterial Pressure: MAP) by non-invasive (indirect) technique using a high definition oscillometric method. Blood pressure was measured in calm animals in lateral recumbency using appropriate size cuffs placed around the median artery of distal forelimb. The average of at least five measurements from each dog was recorded as the final blood pressure. Among breeds, higher SAP, MAP and DAP was recorded in Grey hound. Blood pressure was not influenced by age and sex. End organ risk categorization using value of systolic blood pressure revealed that out of 170 dogs, $42.35 \%, 20.59 \%, 31.18 \%$ and $5.88 \%$ dogs were at minimum risk, mild risk, moderate risk and severe risk respectively. Routine blood pressure monitoring using high definition oscillometer could be helpful in preventing cardiac and renal diseases by assessing end organ risk categorization.
\end{abstract}

HIGHLIGHTS:

(0 Blood pressure in Grey hounds breed was higher as compared to other breeds.

(0 Prevalence of severe hypertension was $5.88 \%$ and it was not influenced by age and sex in healthy dogs.

Keywords: Blood pressure, dogs, high definition oscillometer, systemic hypertension

Blood pressure (BP) is the force that blood exerts against any area of the arterial wall, generally measured in $\mathrm{mmHg}$ (Brown et al., 2007). Systemic arterial BP can be divided into 3 components: systolic arterial BP, mean arterial BP, and diastolic arterial BP. Arterial blood pressure is a common parameter evaluated in conscious and anesthetized animals for assessing the cardiovascular status of an animal and monitoring of disorders such as heart disease, renal disease, and endocrinopathies (Skelding and Valverde, 2020). Although, direct blood pressure measurement (invasive method) is considered as the gold standard method, but it is not convenient in routine clinical practice (Stepien and Rapoport, 1999); so the indirect technique using an oscillometer (non-invasive) makes routine clinical blood pressure measurement practicable in dogs.
High definition oscillometric BP monitors introduce a new technology for non-invasive measurement of arterial BP which can measure BP more accurately than standard oscillometry (Egner, 2015). It has been evaluated in a few veterinary species like anaesthetized dogs, horse and cheetah (Seliskar et al., 2013; Tunsmeyer et al., 2015, Cassia et al., 2015); but studies are lacking in awakened dogs. So, keeping this in view, present study was planned with objective of blood pressure measurement using high definition oscillometric method in apparently healthy conscious dogs.

How to cite this article: Bala, M., Turkar, S., Saini, N., Randhawa, C.S. and Kashyap, N. (2021). High Definition Oscillometric Blood Pressure Measurement in Apparently Healthy Dogs: A Clinical Study. J. Anim. Res., 11(04): 637-641.

Source of Support: None; Conflict of Interest: None 


\section{MATERIALS AND METHODS}

The present study was undertaken in Department of Veterinary Medicine at Multispecialty Veterinary Hospital Guru Angad Dev Veterinary and Animal Sciences University, Ludhiana and approved by the Institutional Animal Ethics Committee (IAEC), Guru Angad Dev Veterinary and Animal Sciences University (GADVASU), Ludhiana, Punjab India (GADVASU/2020/IAEC/53/07). The study was conducted to record blood pressure in apparently healthy conscious dogs of different breeds presented for general routine check-up. A detailed history regarding age, sex, breed etc. was recorded and thorough clinical examination was done. The blood pressure of dogs was measured using high definition oscillometric method (Vet HDO monitor) as per the protocol of American College of Veterinary Internal Medicine (ACVIM) suggested by panel of expert (Acierno et al., 2018). Dogs were gently restrained and the dogs showing obvious signs of stress were excluded from analysis. Blood pressure was measured after the animal was placed in lateral recumbency and acclimatization of the animal in the blood pressure monitoring room for at least 10-15 minutes. Cuffs of different sizes according to circumference of animal's distal forelimb (40\% of the diameter) were selected and blood pressure measurements were taken from the distal forelimb from the median artery. The average of at least five measurements from each dog was recorded as the final blood pressure.

The apparently healthy dogs $(n=170)$ were grouped according to the age into 3 groups, group 1 ( 1 to 4 years, $\mathrm{n}=48$ ), group 2 ( 4 to 8 years, $\mathrm{n}=96$ ), group 3 ( $>8$ years, $\mathrm{n}=26$ ). According to sex, 124 male and 46 female were included in this study. The 170 apparently healthy dogs were also classified according to breed that included both large and small breeds. Among large breeds, Labradors $(\mathrm{n}=87)$ Pit Bull $(\mathrm{n}=14)$, German shepherd $(\mathrm{n}=12)$, Grey hound $(n=4)$, Golden retriever $(n=3)$, Rottweiler $(n=2)$ and Saint Bernard $(n=2)$ and among small breeds, Pugs $(n=26)$ Pomeranian $(n=8)$, Dachshund $(n=4)$, Cocker spaniel $(n=2)$, Beagle $(n=2)$ and mixed breed $(n=4)$ were included in this study.

Hypertension (HTN) was diagnosed based on the guidelines of ACVIM (Acierno et al., 2018) as follows:

\begin{tabular}{llll}
\hline Risk Level & $\begin{array}{l}\text { Systolic } \\
\text { Pressure } \\
(\mathbf{m m} \mathbf{H g})\end{array}$ & $\begin{array}{l}\text { Diastolic } \\
\text { Pressure } \\
(\mathbf{m m} \mathbf{H g})\end{array}$ & $\begin{array}{l}\text { Risk of end } \\
\text { organ } \\
\text { damage }\end{array}$ \\
\hline 1 & $<150$ & $<95$ & Minimal \\
2 & $150-159$ & $95-99$ & Mild \\
3 & $160-179$ & $100-119$ & Moderate \\
4 & $>180$ & $>120$ & Severe \\
\hline
\end{tabular}

The statistical analysis was done using SAS version 9.3 computer software with the help of ANOVA (General Linear Model).

\section{RESULTS AND DISCUSSION}

\section{Breed-wise blood pressure monitoring of apparently healthy dogs}

In this study, no significant difference was observed in the mean values of SAP, DAP and MAP among all breeds (Table 1). In Labrador, the overall mean SAP, DAP and MAP was recorded as $157.61 \pm 1.61,92.30 \pm 1.44$ and $116.58 \pm 1.34 \mathrm{~mm} \mathrm{Hg}$, respectively, while in Pug dogs, the overall mean SAP, DAP and MAP was recorded as $150.55 \pm 3.27,85.96 \pm 3.16$ and $108.65 \pm 3.25 \mathrm{~mm} \mathrm{Hg}$, respectively (Table 1). In Grey hounds, the mean values of SAP, DAP and MAP was higher (statistically nonsignificant, $\mathrm{p}<0.01$ ) as compared to other breeds and value of mean SAP, DAP and MAP were 175.25 \pm 9.56 , $92.75 \pm 6.76$ and $118.10 \pm 6.87 \mathrm{~mm} \mathrm{Hg}$, respectively.

Bodey and Mitchell (1996) recorded SAP and DAP in Labrador, German shepherd and Pomeranian as $118 \pm 17,66 \pm 13 ; 132 \pm 13,75 \pm 10 ; 136 \pm 12,76 \pm 13 \mathrm{~mm}$ $\mathrm{Hg}$, respectively. They also found that the blood pressure of breeds other than Sight hounds vary by $7-10 \mathrm{~mm}$ $\mathrm{Hg}$. The present study findings were in agreement with Singla (2015), who reported that there was no significant difference in SAP, DAP and MAP mean values among the Labrador, German shepherd and Pomeranian dogs.

Findings of present study were in accordance with Schneider et al. (1964), who reported that healthy sight hounds (Grey hounds) have a higher normal range of blood pressure, which might be upto $15 \mathrm{~mm}$ higher than other breeds, as alterations in the RAAS and lower aldosterone concentration in Greyhounds are associated with hemodynamic and clinicopathologic differences 
Table 1: Breed-wise blood pressure monitoring of apparently healthy dogs (Mean $\pm \mathrm{SE}$ )

\begin{tabular}{llll}
\hline Breed $(\mathbf{n}=\mathbf{1 7 0})$ & SAP $(\mathbf{m m ~ H g})$ & DAP $(\mathbf{m m} \mathbf{H g})$ & MAP $(\mathbf{m m} \mathbf{H g})$ \\
\hline Labrador $(\mathrm{n}=87)$ & $157.61 \pm 1.61$ & $92.30 \pm 1.44$ & $116.58 \pm 1.34$ \\
Pug $(\mathrm{n}=26)$ & $150.55 \pm 3.27$ & $85.96 \pm 3.16$ & $108.65 \pm 3.25$ \\
Pit Bull (n=14) & $149.09 \pm 3.48$ & $86.79 \pm 2.86$ & $111.29 \pm 2.93$ \\
German Shepherd $(\mathrm{n}=12)$ & $150.60 \pm 4.05$ & $87.90 \pm 3.53$ & $111.47 \pm 2.65$ \\
Pomeranian (n=8) & $151.73 \pm 5.11$ & $81.25 \pm 2.94$ & $106.88 \pm 3.13$ \\
Dachshund (n=4) & $161.85 \pm 11.18$ & $92.85 \pm 9.56$ & $120.05 \pm 8.71$ \\
Grey hound (n=4) & $175.25 \pm 9.56$ & $92.75 \pm 6.76$ & $118.10 \pm 6.87$ \\
Golden retriever (n=3) & $161.73 \pm 7.90$ & $89.40 \pm 6.31$ & $117.53 \pm 7.58$ \\
Cocker spaniel (n=2) & $152.40 \pm 21.00$ & $81.70 \pm 8.30$ & $106.30 \pm 12.50$ \\
Rottweiler (n=2) & $152.90 \pm 7.30$ & $93.90 \pm 15.50$ & $113.90 \pm 11.10$ \\
Beagle (n=2) & $154.10 \pm 9.30$ & $90.20 \pm 5.80$ & $113.10 \pm 7.10$ \\
Saint Bernard $(\mathrm{n}=2)$ & $166.30 \pm 11.70$ & $95.10 \pm 1.30$ & $119.60 \pm 4.00$ \\
Miscellaneous $(\mathrm{n}=4)$ & $151.25 \pm 7.36$ & $82.05 \pm 1.95$ & $107.20 \pm 3.19$ \\
\hline
\end{tabular}

which leads to higher serum sodium concentration and blood pressure, suggesting that angiotensin II effects in the renal tubule predominate over those of aldosterone (Martinez et al., 2017).

\section{Age-wise blood pressure monitoring in apparently healthy dogs}

Age-wise (Mean $\pm \mathrm{SE}$ ), SAP, DAP, and MAP are depicted in table 2. In present study, the differences in blood pressureamong various age groups did not show any significant difference

Table 2: Age-wise blood pressure monitoring in apparently healthy dogs (Mean \pm SE)

\begin{tabular}{llll}
\hline Age $(\mathbf{n}=\mathbf{1 7 0})$ & $\begin{array}{l}\text { SAP }(\mathbf{m m} \text { of } \\
\mathbf{H g})\end{array}$ & $\begin{array}{l}\text { DAP }(\mathbf{m m} \\
\text { of } \mathbf{H g})\end{array}$ & $\begin{array}{l}\text { MAP }(\mathbf{m m} \\
\text { of } \mathbf{H g})\end{array}$ \\
\hline 1-4 years $(\mathrm{n}=48)$ & $152.48 \pm 2.31$ & $87.56 \pm 1.93$ & $110.68 \pm 1.89$ \\
4-8 years $(\mathrm{n}=96)$ & $156.77 \pm 1.63$ & $89.61 \pm 1.37$ & $114.46 \pm 1.33$ \\
$>8$ years $(\mathrm{n}=26)$ & $157.54 \pm 3.14$ & $93.86 \pm 2.63$ & $117.60 \pm 2.56$ \\
\hline
\end{tabular}

Systemic hypertension occurs frequently in the aging population in humans. The prevalence of hypertension increases with age and is thought to be due to an age-related loss of arterial compliance secondary to progressive decreases in the distensibility and elasticity of the large capacitance arteries (Oliveros et al., 2020). But, systemic hypertension does not occur secondary to the aging process in the dogs as reported by various workers (Meurs et al., 2000; Mishina et al., 1997; PerezSanchez et al., 2015). Whereas, Bodey and Michell (1996) reported higher systolic blood pressure (SBP) in older age group. In their study, no attempts were made to screen the participating animals for underlying disease such as renal and heart diseases. Since, these disease processes can be chronic and may have long asymptomatic periods, it is possible that the geriatric dogs in that study might have had elevated blood pressures due to undiagnosed, underlying disease processes that led to systemic hypertension.

\section{Sex-wise blood pressure monitoring in apparently healthy dogs}

The overall mean SAP, DAP and MAP of male dogs were $155 \pm 1.44,88.65 \pm 1.17$ and $112.84 \pm 1.18 \mathrm{~mm} \mathrm{Hg}$, respectively, while in female dogs, the overall mean SAP, DAP and MAP were $157.50 \pm 2.36,92.47 \pm 2.13$ and $116.66 \pm 1.93 \mathrm{~mm} \mathrm{Hg}$, respectively. In present study, the differences in blood pressure between the male and female were statistically non-significant.

Bodey and Michell (1996) reported higher systolic blood pressure (SBP) in intact male dogs as compared to neutered male dogs and intact bitches. Similarly, in human beings, males are more prone for hypertension than females. Observed gender differences in hypertension, which exist in human and animal populations, are due to both biological and behavioral factors (Sandberg and Ji, 2012). The biological factors include sex hormones, chromosomal 
differences, and other biological sex differences that are protective against hypertension in female. Behavioral risk factors for hypertension include high body mass index (BMI) and low physical activity (Everett and Zajacova, 2015).

The present study findings are in agreement with PerezSanchez et al. (2015) and Singla (2015) who reported that a correlation between gonadal statuses and HTN was not evident in their study. The data presented here would appear to be higher to data presented in the study of Singla (2015) who reported mean SAP $(131 \pm 1.85 \mathrm{~mm} \mathrm{Hg})$, DAP $(74 \pm 1.43 \mathrm{~mm} \mathrm{Hg})$ and MAP $(93 \pm 1.69 \mathrm{~mm} \mathrm{Hg})$ in male dogs and mean SAP $(130 \pm 2.35 \mathrm{~mm} \mathrm{Hg})$, DAP $(75 \pm 2.49$ $\mathrm{mm} \mathrm{Hg})$ and MAP $(93 \pm 2.16 \mathrm{~mm} \mathrm{Hg})$ in female. The differences in blood pressure in healthy dogs might be due to the use of standard oscillometer (Surgivet V60046) in their study, which utilizes algorithms to compute systolic and diastolic arterial BP, whereas high definition oscillometry used in present study, directly measures systolic, mean, and diastolic arterial BP values.

\section{Risk-wise categorization of target organ damage in apparently healthy dogs}

The results of percentage risk-wise categorization in 170 apparently healthy dogs are shown in table 3. According to the Hypertension consensus panel, American College of Veterinary Internal Medicine recommendations for the classification of patients as per risk of end organ damage on the basis of SAP, 72/170 (42.35\%) dogs with mean SAP $(141.34 \pm 1.02)$ were at the category of minimal risk, $35 / 170$ (20.59\%) dogs with mean SAP (155.58 \pm 1.10$)$ were at mild risk category, 53/170 (31.18\%) dogs with mean SAP $(169.11 \pm 0.86)$ were at moderate risk category and 10/170 (5.88\%) with mean SAP (186.38 1.98$)$ dogs were at severe risk.

Diastolic blood pressure-wise risk categorization revealed that $114 / 170(67.06 \%)$ dogs with mean DAP $(85.04 \pm 0.88)$ were at the minimal risk category, 23/170 (13.53\%) dogs with mean DAP $(99.76 \pm 1.47)$ were at mild risk, 30/170 $(17.65 \%)$ dogs with mean DAP $(108.64 \pm 1.25)$ were at moderate risk and 3/170 (1.76\%) dogs with mean DAP $(119.70 \pm 0.10)$ were at severe risk category.

Remillard et al. (1991) observed 10\% prevalence of hypertension in apparently healthy dogs. Bodey and Michell (1996) reported that dogs are resistant to the development of primary hypertension. Brown et al. (2007) stated that high blood pressure in otherwise animals, particularly young animals, should be assumed to be white coat effect until and unless proven otherwise. Singla (2015) reported that 93/110 (84.5\%) dogs were in minimal risk category, $14 / 110(12.72 \%)$ dogs were in mild risk category and $3 / 110(2.72 \%)$ were in moderate risk category and none of the dogs in severe risk category. The findings of present study revealed $5.88 \%$ prevalence of severe hypertension among apparently healthy dogs. The possible reason might be the presence of some overweight/obese dogs along with normal weight dogs in this study. Montoya et al. (2006) suggested that weight status must be considered as a risk factor for secondary hypertension. Tropf et al. (2017) observed increased median SBP (160 mm Hg) in obese dogs as compared with lean dogs $(145 \mathrm{~mm} \mathrm{Hg})$ and higher frequency of HTN in obese patients. The mechanisms by which obesity causes HTN are complex and involve several organic mechanisms such as: activation of the renin-angiontensinaldosterone system (RAAS), an increase in the activity of the sympathetic nervous system (Perez-Sanchez et

Table 3: Percentage risk-wise categorization of blood pressure in apparently healthy dogs (Mean $\pm \mathrm{SE}$ )

\begin{tabular}{|c|c|c|c|c|}
\hline \multicolumn{5}{|c|}{ SAP } \\
\hline $\begin{array}{l}\text { Risk category } \\
(n=170)\end{array}$ & $\begin{array}{l}\text { Minimal risk }(<150 \mathrm{~mm} \\
\text { of } \mathrm{Hg})(\mathrm{n}=72)\end{array}$ & $\begin{array}{l}\text { Mild risk }(150-159 \mathrm{~mm} \\
\text { of } \mathrm{Hg})(\mathrm{n}=35)\end{array}$ & $\begin{array}{l}\text { Moderate risk }(160-179 \\
\mathrm{mm} \text { of } \mathrm{Hg})(\mathrm{n}=53)\end{array}$ & $\begin{array}{l}\text { Severe risk }(>179 \mathrm{~mm} \text { of } \\
\mathrm{Hg})(\mathrm{n}=10)\end{array}$ \\
\hline SAP & $42.35 \%$ & $20.59 \%$ & $31.18 \%$ & $5.88 \%$ \\
\hline \multicolumn{5}{|c|}{ DAP } \\
\hline $\begin{array}{l}\text { Risk category } \\
(n=170)\end{array}$ & $\begin{array}{l}\text { Minimal risk }(<95 \mathrm{~mm} \\
\text { of } \mathrm{Hg})(\mathrm{n}=114)\end{array}$ & $\begin{array}{l}\text { Mild risk (95-99 } \mathrm{mm} \text { of } \\
\mathrm{Hg})(\mathrm{n}=23)\end{array}$ & $\begin{array}{l}\text { Moderate risk }(100- \\
119 \mathrm{~mm} \text { of } \mathrm{Hg})(\mathrm{n}=30)\end{array}$ & $\begin{array}{l}\text { Severe risk }(>119 \mathrm{~mm} \text { of } \\
\mathrm{Hg})(\mathrm{n}=3)\end{array}$ \\
\hline DAP & $67.06 \%$ & $13.53 \%$ & $17.65 \%$ & $1.76 \%$ \\
\hline
\end{tabular}


al., 2015). The mechanisms that are responsible for an increased sympathetic activity in obesity include impaired function of the baroreceptor sensitivity, increased levels of circulating free-fatty acids (FFAs), angiotensin (Ang) II, insulin and leptin (Kotsis et al., 2010).

\section{CONCLUSION}

It can be concluded that high definition oscillometer is a useful non-invasive technique for blood pressure monitoring in dogs for routine clinical practice. Grey hound breed dogs have higher SAP, DAP and MAP. There is no effect of age and gender on blood pressure in dogs. According to hypertension risk, only $5.88 \%$ healthy dogs are at severe risk category.

\section{REFERENCES}

Acierno, M.J., Brown, S., Coleman, A.E., Jepson, R.E., Papich, M., Stepien, R.L. and Syme, H.M. 2018. ACVIM consensus statement: Guidelines for the identification, evaluation, and management of systemic hypertension in dogs and cats. $J$. Vet. Intern. Med., 32: 1803-22.

Bodey, A.R. and Michell, A.R. 1996.Epidemiological study of blood pressure in domestic dogs. J. Small Anim. Pract., 37: 116-25.

Brown, S., Atkins, C., Bagley, R., Carr, A., Cowgill, L., Davidson, M., Egner, B., Elliott, J., Henik, R., Labato, M., Littman, M., Polzin, D., Ross, L., Snyder, P. and Stepien, R. 2007. Guidelines for the identification, evaluation, and management of systemic hypertension in dogs and cats. $J$. Vet. Intern. Med., 21: 542-58.

Cassia, E.V.S., Boswood, A., Tordiffe, A.S.W. 2015.Comparison of high definition oscillometric and direct arterial blood pressure measurement in anesthetized cheetahs (Acinonyx jubatus). J. Zoo Wildl. Med., 46: 506-516.

Egner, B. 2015. High definition oscillometry: non-invasive blood pressure measurement and pulse wave analysis. Principles of Safety Pharmacology, pp. 243-264. Springer, Berlin, Heidelberg.

Everett, B. and Zajacova, A. 2015. Gender differences in hypertension and hypertension awareness among young adults. Biodemography Soc. Biol., 61(1): 1-17.

Kotsis, V., Stabouli, S. and Papakatsika, S. 2010. Mechanism of obesity-induced hypertension. Hypertension, 33: 386-393.

Martinez, J., Kellogg, C., Iazbik, M.C., Couto, C.G., Pressler, B.M., Hoepf, T.M. and Radin, M.J. 2017. The reninangiotensin-aldosterone system in Greyhounds and nonGreyhound dogs. J. Vet. Intern. Med., 31: 988-993.
Meurs, K.M., Miller, M.W., Slater, M.R. and Glaze, K. 2000. Arterial blood pressure measurement in a population of healthy geriatric dogs. J. Am. Anim. Hosp. Assoc., 36(6): 497-500.

Mishina, M., Watanbe, T., Fujii, K., Maeda, H., Wakao, Y. and Takahashi, M. 1997. A clinical evaluation of blood pressure through non invasive measurement using the Oscillometric procedure in conscious dogs. J. Vet. Med. Sci., 59(11): 98993.

Montoya, JA., Morris, P.J. and Bautista, I. 2006. Hypertension: a risk factor associated withweight status in dogs. J. Nutr., 136: 2011S-2013S.

Oliveros, E., Patel, H., Kyung, S., Fugar, S., Goldberg, A., Madan, N. and Williams K.A. 2020. Hypertension in older adults: assessment, management, and challenges. Clin. Cardiol., 43: 99-107.

Perez-Sanchez, A.P., Del-Angel-Caraza, J., Quijano-Hernandez, I.A. and Barbosa- Mireles, M.A. 2015. Obesity-hypertension and its relation to other diseases in dogs. Vet. Res. Comm., 39: 45-51.

Remillard, R.L., Ross, J.N. and Eddy, J.B. 1991.Variance of indirect blood pressure measurements and prevalence of hypertension in clinically normal dogs. Am. J. Vet. Res., 52: 561-565.

Sandberg, K. and Ji, H. 2012. Sex differences in primary hypertension. Biol. Sex Differ, 3(1): 7.

Schneider, H.P., Truex, R.C. and Knowles, J.O. 1964. Comparative observations of the hearts of mongrel and greyhound dogs. Anat. Rec., 149: 173-180.

Seliskar, A., Zrimsek, P., Sredensek, J. and Petric, A.D. 2013. Comparison of high definition oscillometric and Doppler ultrasound devices with invasive blood pressure in anaesthetized dogs. Vet. Anaesth. Analg., 40: 21- 27.

Singla, G. 2015. Studies on prevalence and therapeutic management of hypertension in dogs. M.V.Sc. thesis. Guru Angad Dev Veterinary and Animal Sciences University, Ludhiana, India.

Skelding, A. and Valverde, A. 2020. Non-invasive blood pressure measurement in animals: Part 1-Techniques for measurement and validation of non-invasive devices. Can. Vet. J., 61(4): 368-74.

Stepien, R.L. and Rapoport, G.S. 1999. Clinical comparison of three methods to measure blood pressure in nonsedated dogs. J. Am. Vet. Med. Assoc., 215: 1623-28.

Tropf, M., Nelson, O.L., Lee, P.M. and Weng, H.Y. 2017. Cardiac and metabolic variables in obese dogs. J. Vet. Int. Med., 31(4): 1000-1007.

Tunsmeyer, J., Hopster, K., Feige, K. and Kästner, S.B. 2015. Agreement of high definition oscillometry with direct arterial blood pressure measurement at different blood pressure ranges in horses under general anaesthesia. Vet. Anaesth. Analg., 42: 286-291. 
